the highest gold content found by F. Haber and co-workers (in water from the East Greenland polar current) was $0.04 \mathrm{mgm}$./ton, the average value for the South Atlantic surface water being at least ten times less.

Hans Pettersson.

Oceanografiska Institutet,

Göteborg.

March 29.

\section{Rhythmical Impedance Changes in the Trout's Egg}

Many measurements have been made in recent years of the electrical impedance of cells such as those of nerve, Nitella and of marine eggs, and it has been found that such measurements yield valuable information as to cellular structure and reactivity.

Fertilized and unfertilized trout's eggs undergo rhythmical impedance changes when they have been in water for about six hours ${ }^{1}$. Further experiments show that this effect is not associated with the cytochrome system, as sodium nitride, carbon monoxide and lack of oxygen do not affect it. On the other hand, suitable concentrations of phenyl urethane reversibly abolish the effect. The action of the anæsthetic is shown in Fig. 1. The recovery part of the record has been omitted as it has no features of special interest.

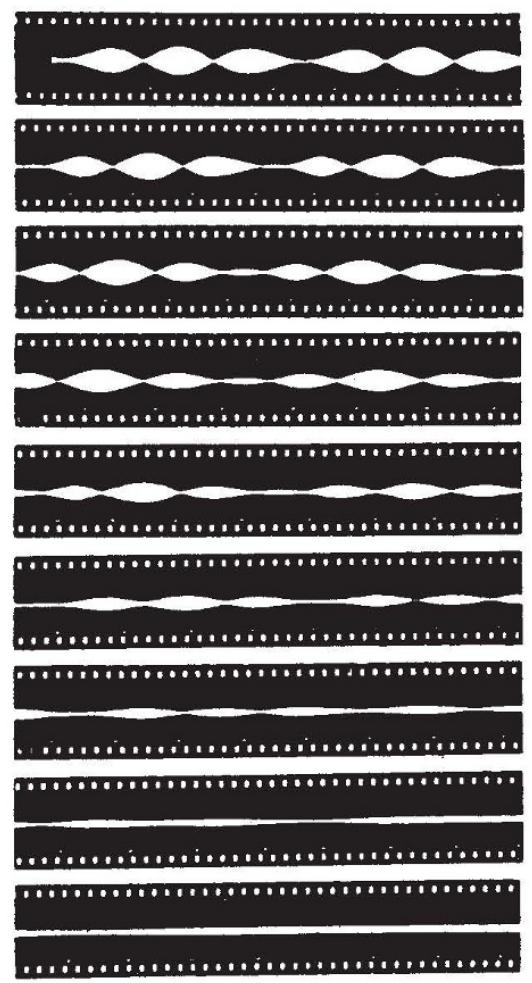

Fig. 1.

THE RFFECT OF PHENYL URETHANE ON THE IMPEDANCE OYCLE IN AN UNFERTILIZED TROUT EGG. THE ANAFSTHETIC WAS APPLIED AT THE BEGINNING OF THE RECORD. TIME-MARKER, MinUtes. (a)

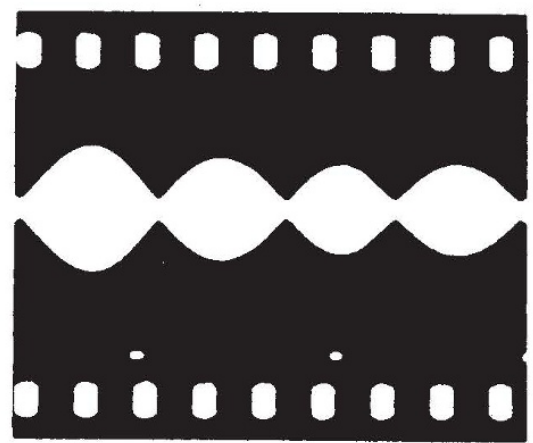

(b)
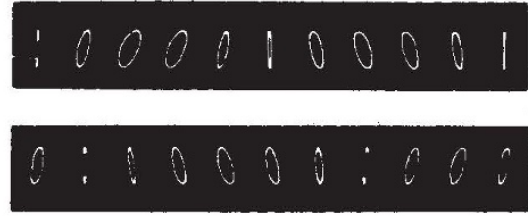

Fig. 2.

$a$, TWo COMPLETE IMPEDANCE CYCles. TIMEMARKER, MINUTES.

$b$, SIMULTANEOUS RECORD OF THE RESISTANCE AND CAPACITANCE CHANGES IN THE EQUIVALENT CIRCUIT. The Ellipses ARE $7 \cdot 5$ SEC. APART.

A change in impedance is due to a change in resistance and/or capacitance. (Inductances need not at present be considered in biological systems.) By using the 'ellipse' method of resolution', one can evaluate the resistive and capacitative components of the egg impedance cycle in the parallel circuit equivalent at a particular frequency to the trout egg in tap-water. This is shown in Fig. 2. Here, simultaneous moving film records of the impedance cycle, the resistive $\left(R_{p}\right)$ and the capacitative $\left(C_{p}\right)$ components are recorded. If $R_{p}$ (as the angle of tilt of the ellipse) and $C_{p}$ (as the minor ellipse axis) are plotted against time, the resultant curves are in phase every other cycle and approximately sinusoidal.

Zoological Laboratory,

ROTHSCHILD.

Cambridge.

March 23.

${ }^{1}$ Hubbard and Rothschild, Proc. Roy. Soc., B, 127, 510 (1939).

${ }^{2}$ Cole, K. S., and Curtis, H. S., J. Gen. Physiol., 22, 37 (1938).

\section{Fluorescence and Oxidation in Conjugated Ring Systems}

The study of the fluorescence of organic substances has shown that strong fluorescence is almost entirely confined to conjugated ring systems, which possess the highly mobile electrons. Theoretically, it is clear that a substance can only then exhibit fluorescence if the potential curves of the ground state and the excited state do not cross each other (or come very near to each other) so that the transformation of electronic excitation energy into heat cannot occur.

Thus the essential conditions for fluorescence are : (1) the excitation of the electron must not change appreciably the internuclear distance; (2) there must be no favoured position for the electron where it can be 'trapped' and thereby its kinetic energy transformed into potential energy. 